\title{
Polychlorinated Biphenyls (PCBs) Inhibit Hepcidin Expression through an Estrogen-Like Effect Associated with Disordered Systemic Iron Homeostasis
}

\author{
Yi Qian, ${ }^{\dagger} \ddagger$ Shuping Zhang, ${ }^{\ddagger} \S$ Wenli Guo ${ }^{\ddagger}$ Juan Ma, ${ }^{\ddagger}$ Yue Chen, ${ }^{\ddagger}$ Lei Wang, ${ }^{\ddagger}$ Meirong Zhao, ${ }^{\dagger} \dagger$ \\ and Sijin $\mathrm{Liu}^{*}+*$ \\ ${ }^{\dagger}$ College of Biological and Environmental Engineering, Zhejiang University of Technology, Hangzhou 310032, China \\ ${ }^{\ddagger}$ State Key Laboratory of Environmental Chemistry and Ecotoxicology, Research Center for Eco-Environmental Sciences, Chinese \\ Academy of Sciences, Beijing 100085, China \\ ${ }^{\S}$ Institute for Medical Engineering and Science, Massachusetts Institute of Technology, Cambridge, Massachusetts 02139, United \\ States
}

\begin{abstract}
Polychlorinated biphenyls (PCBs), with 209 congeners, are a large family of persistent organic pollutants. PCBs elicit a wide range of toxicities, such as neurotoxicity, hepatoxicity, oncogenicity, and endocrine-disrupting effects. However, an understanding of the potential disruption of systematic iron metabolism by PCBs is still limited. To maintain iron homeostasis, the hepcidin-ferroportin (FPN) axis is critically important, and hepcidin is the central governor in guiding dietary iron absorption and iron egress from macrophages. Hepcidin is secreted by hepatocytes and binds to FPN to promote its degradation. Dysregulation of hepcidin gives rise to disordered iron homeostasis, associated with diverse diseases including anemia and $\beta$-thalassemia. Our previous study demonstrated that there is an estrogen response element (ERE) within the promoter of hepcidin gene and that its expression is regulated by estrogen. In the current study, we demonstrated that both PCB153 and PCB126 greatly suppress hepcidin expression in HepG2 cells, with a greater repression occurring in cells upon PCB126 treatment. Further studies uncovered that both PCB153 and PCB126 harbor estrogenic activity and that the estrogenic activity of PCB126 was stronger than that of PCB153 in HepG2 cells. Mechanistic investigation revealed that PCBs suppress hepcidin transcription through a functional ERE within the hepcidin promoter, analogous to the action of $17 \beta$-estradiol. Moreover, hepatic hepcidin was downregulated in wild-type mice upon PCB126 administration, coupled with elevated serum iron content as well as reduced hepatic and splenic iron mass. These changes were not replicated in hepcidindeficient mice upon PCB administration. Additionally, hepatocytes were observed with severe accumulation of lipid droplets in the livers of mice challenged with PCB126, irrespective of the presence of hepcidin. To summarize, our results have deciphered a suppressive role of PCBs in restraining the expression of hepcidin through mimicking estrogenic activity and revealed a novel property of $\mathrm{PCB}$ in disrupting systemic iron metabolism. This study also unearthed a PCB-mediated connection linking estrogen-like activity, iron effects, and lipid homeostasis.
\end{abstract}

\section{INTRODUCTION}

Polychlorinated biphenyls (PCBs) are a large family of persistent environmental pollutants with diverse structures. PCBs were initially produced for industrial applications due to their excellent lubricating and heat conducting properties. ${ }^{1}$ Although their production has been banned since the late 1970s, PCBs are still found at relatively high levels in water, animals, and humans because of their persistence and bioaccumulation in the environment. ${ }^{2,3}$ Among the widely distributed PCBs, PCB153 and PCB126 are among the most pronounced ones found in the global ecosystem. ${ }^{4}$ Nonplanar PCB153, one of the most abundant PCB congeners, is considered to be a canonical representative $\mathrm{PCB}$ congener. By contrast, coplanar PCB126, which is less abundant than
PCB153, is recognized as being a more toxic PCB congener. ${ }^{5}$ To date, the biochemical and toxic effects of commercial PCBs have been largely studied in a number of laboratory animals and wildlife species. These studies indicated that PCBs might undermine the functions of the immune, nervous, and endocrine systems ${ }^{6}$ and even increase the risk of cancers. ${ }^{7}$ Similar to other endocrine-disrupting compounds, PCBs are capable of mimicking estrogenic activity by disrupting the functions of various organs. ${ }^{8}$ Specifically, some $\mathrm{PCB}$ congeners (including PCB77 and PCB126) have been demonstrated to exhibit significant biological activity and disrupt endogenous ER

Received: October 20, 2014

Published: February 16, 2015 
signaling. ${ }^{8-11}$ For instance, PCB126 exhibits a strong estrogenlike effect by inducing the expression of estrogen receptor $\alpha$ $(\mathrm{ER} \alpha)$ and hijacking it to promote $\mathrm{ER} \alpha$-centered transcription. ${ }^{10,11}$ Meanwhile, PCB153 has also been demonstrated to possess a similar but weaker capability to activate ER signaling. ${ }^{12}$ Although a large number of studies have documented the estrogen-like property of PCBs, the findings are not consistent, and some results are even controversial. ${ }^{13,14}$ This discrepancy could be due to the distinct exposure concentrations, experimental strategies, and cell types used in the different studies. Therefore, the close characterization of this property is warranted in each individual study.

Iron, a crucial chemical in the environment, is essential to nearly all forms of life. Iron is a necessary component for myriad proteins involved in numerous functions, e.g., electron transfer in the respiratory chain, RNA transcription, enzymatic activities in metabolism, and DNA synthesis. ${ }^{15,16}$ It is critical to maintain iron homeostasis in a concerted balance, otherwise iron overload or iron deficiency would result, which is detrimental to the body. ${ }^{17}$ Regarding the regulation of systemic iron homeostasis, the hepcidin-ferroportin (FPN) axis plays a central role. ${ }^{18}$ Hepcidin is a 25 amino acid peptide secreted by hepatocytes and is a key hormone in governing iron dietary absorption and iron release from macrophages through binding to its receptor, FPN, and subsequently inducing the degradation of FPN. ${ }^{19}$ FPN is the only known iron exporter in mammalian cells thus far, with prominent expression in enterocytes, hepatocytes, and macrophages. ${ }^{18}$ Direct binding of hepcidin to FPN on the plasma membrane limits iron egress through inducing FPN's internalization and ubiquitin-mediated degradation. ${ }^{20}$ Increased hepcidin gives rise to FPN degradation, resulting in diminished iron absorption in the duodenum and restricted iron export from macrophages associated with reduction of serum iron and concurrent iron retention in organs such as the spleen. ${ }^{19}$ Thus, excessive hepcidin would limit iron availability for hemoglobin production. In support of this, transgenic mice overexpressing hepcidin were very anemic due to iron-restricted erythropoiesis. ${ }^{21}$ In contrast, hepcidin deficiency provokes FPN function coupled to dietary iron hyperabsorption and enhanced iron release from macrophages, resulting in iron overload in organs, as evidenced in patients with hereditary hemochromatosis. ${ }^{18,22}$

Our previous study found that PCB77, a PCB congener that resembles PCB126, can disturb iron homeostasis, ${ }^{23}$ although no mechanistic insight into the molecular basis of this has been uncovered. In the current study, we endeavored to elucidate the molecular mechanism responsible for PCB's disruption of iron homeostasis. Our combined data revealed a novel finding that PCB153 and PCB126 disrupt systemic iron homeostasis by repressing hepcidin expression through their estrogen-like activity. This study is of significance for understanding PCBinduced health effects (such as tumor effects) from the angle of disordered iron homeostasis.

\section{MATERIALS AND METHODS}

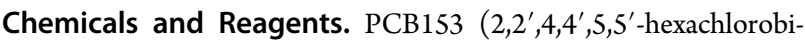
phenyl) and PCB126 (3,3',4',4',5-pentachlorobiphenyl) were purchased from AccuStandard Inc. TCDD (2,3,7,8-tetrachlorodibenzo- $p$ dioxin) was purchased from Cerilliant Inc. 17 $\beta$-Estradiol (E2) and tamoxifen were purchased from Sigma-Aldrich Co. Heparin (heparin sodium salt) was obtained from (Sigma-Aldrich) and was dissolved in PBS. Dimethyl sulfoxide (DMSO) (Solarbio Inc., Beijing, China) was used to dissolve PCB153/PCB126, $17 \beta$-estradiol, and tamoxifen. The final concentration of DMSO was $<0.1 \%$ in culture medium.
Cell Culture. Human hepatocarcinoma HepG2 cells were purchased from the Shanghai Cell Bank of Type Culture Collection of the Chinese Academy of Sciences. Cells were grown in RPMI 1640 medium (Gibco), supplemented with $10 \%$ fetal bovine serum (FBS, Gibco), at $37{ }^{\circ} \mathrm{C}$ under $5 \% \mathrm{CO}_{2}$, as previously described. ${ }^{24}$ With respect to the experiments with $17 \beta$-estradiol, charcoal-treated FBS (GEMINI Inc.) was used for all work.

Cytotoxicity Assay. Cell viability was assessed through an MTT assay following the instructions from the manufacturer (Roche). In brief, cells were first starved with $1 \%$ serum overnight and were then seeded in 96-well plates (5000 cells/well) followed by different treatments. After culture for another $24 \mathrm{~h}, 20 \mu \mathrm{L}$ of MTT $(5 \mathrm{mg} / \mathrm{mL})$ was added into each well, and the cells were incubated for $4 \mathrm{~h}$. Thereafter, the medium with MTT was aspirated, and $200 \mu \mathrm{L}$ of DMSO was added into each well. Finally, 96-well plates were read at $490 \mathrm{~nm}$ on a microplate reader (Thermo).

With respect to lactate dehydrogenase (LDH) measurement, cell culture medium was collected $24 \mathrm{~h}$ after treatment. Extracellular levels of $\mathrm{LDH}$ in each well were determined with a CytoTox-ONETM homogeneous membrane integrity assay kit following the manufacturer's instructions (Promega).

Real-Time RT-PCR Analysis. Total RNA from cells or mouse liver tissues was isolated with Trizol reagent following the manufacturer's instructions (Invitrogen, USA). Liver tissues were first milled in liquid nitrogen prior to RNA extraction. Relative gene expression was measured using SYBR green master mix (Qiagen, USA) on a qRTPCR machine (Bio-Rad). Primer sequences for PCR reactions were as follows. Mouse hepcidin, forward: 5'-CTGAGCAGCACCACCTATCTC-3', reverse: 5'-TGGCTCTAGGCTATGTTTTGC-3'; mouse GAPDH, forward: 5'-TGGCAAAGTGGAGATTGTTGCC3', reverse: 5'-AAGATGGTGATGGGCTTCCCG-3'; human hepcidin, forward: 5'-CTTCCCCATCTGCATTTTCTGCT-3', reverse: 5'-CCAGCCATTTTATTCCAAGACCTATG-3'; human IL-6, forward: 5'-CCAGAGCTGTGCAGATGAGT-3', reverse: 5' CTGCAGCCACTGGTTCTGT-3'; human BMP-6, forward: 5'ATCACGGCCACTAGCAATCTG-3', reverse: 5'- CTGAAGCCCCATGTTATGCTG-3'; and human GAPDH, forward: $5^{\prime}$ GAAGGTGAAGGTCGGAGT-3'， reverse: 5'-GAAGATGGTGATGGGATTTC-3'. GAPDH was used as an internal control to determine the relative expression of the target genes.

Reactive Oxygen Species (ROS) Determination. To quantify the intracellular ROS level, cells were first treated with PCBs. Afterward, $10 \mu \mathrm{M}$ 2,7-dichlorodihydrofluorescein diacetate (DCF-DA, Sigma) was added to the culture medium. After a 30 min incubation in the dark, cells were washed twice with cold PBS. DCF fluorescence was detected at $525 \mathrm{~nm}$ with excitation at $488 \mathrm{~nm}$. $0.1 \% \mathrm{H}_{2} \mathrm{O}_{2}$ was used as a positive control to stimulate ROS generation in HepG2 cells.

Western Blotting. Extraction of total proteins was performed with ice-cold RIPA lysis buffer (Solarbio, China) containing a protease inhibitor cocktail (Roche). An equal amount of each lysate (80-100 $\mu \mathrm{g} /$ sample) was subjected to $10 \%$ SDS-PAGE and western blot analysis, as described previously. ${ }^{25}$ Antibodies used here were against GAPDH (1:1000, Santa Cruz Biotechnology), FPN (1:500, Sigma), and ferritin light chain (1:500, Abcam, USA).

Plasmids. The luciferase reporter plasmid pERE-AUG-Luc+ (including three copies of the Xenopus laevis vitellogenin A estrogen responsive element and the rat $\alpha 2 \mathrm{u}$ globulin promoter) and the overexpression vector $\mathrm{rER} \alpha / \mathrm{pCI}$ (containing the full open reading frame of rat $\mathrm{ER} \alpha \mathrm{cDNA}$ ) were generously provided by Dr. M. Takeyoshi (Chemicals Assessment Center, Chemicals Evaluation and Research Institute, Oita, Japan). ${ }^{26}$ These constructs have been established for use in an ER reporter gene assay. ${ }^{27}$ The plasmids for the hepcidin promoter reporter were constructed by our laboratory. ${ }^{28}$ The pGL3-based plasmid containing the hepcidin promoter with the ERE ( $5^{\prime}$-AGTCA-GGC-TGTCC-3'; $-1244 /-1232$ in the promoter region of human hepcidin gene) or the plasmid containing the hepcidin promoter without the ERE was termed pro + ERE or pro $\Delta$ ERE, respectively.

Luciferase Reporter Assay. HepG2 cells were first inoculated in 24-well plates. To assess estrogen activity, $25 \mathrm{ng}$ of $\mathrm{rER} \alpha / \mathrm{pCI}$ and 145 
(A)

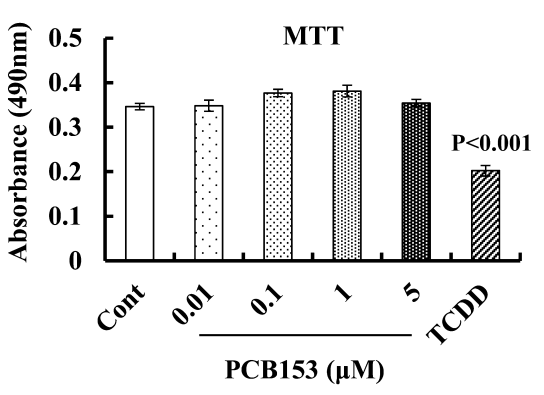

(B)

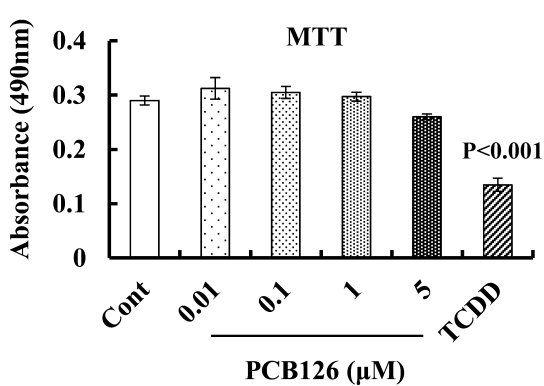

(C)

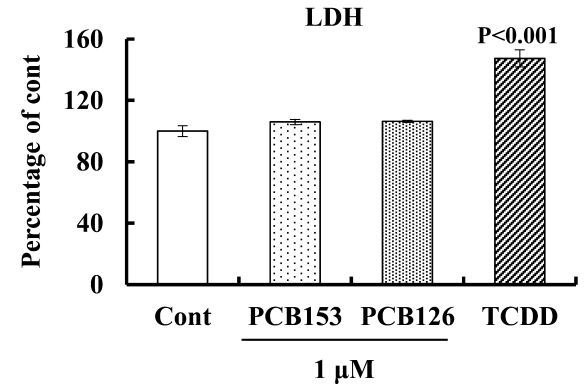

Figure 1. Cytotoxicity of PCB153 and PCB126 in HepG2 cells. HepG2 cells were treated with (A) PCB153 or (B) PCB126 at different concentrations for $24 \mathrm{~h}$, followed by MTT assay $(n=6)$. (C) Membrane integrity was measured by the release of LDH from HepG2 cells after PCB153/PCB126 treatment at $1 \mu \mathrm{M}$ for $24 \mathrm{~h}(n=6)$. TCDD at $5 \mu \mathrm{M}$ was here used as a positive control.

ng of pERE-AUG-Luc+ were cotransfected into cells with $80 \mathrm{ng}$ of Renilla luciferase plasmid using Lipofectamine 2000 on the basis of the instructions from the manufacturer (Invitrogen). Optionally, to determine the activity of the hepcidin promoter, cells were cotransfected with $0.8 \mu \mathrm{g}$ of target plasmid and $80 \mathrm{ng}$ of Renilla luciferase plasmid. After $6 \mathrm{~h}$ of transfection, culture medium was removed and replaced with fresh phenol red-free RPMI 1640 with $5 \%$ charcoal-treated FBS. Afterward, cells were treated with $1 \mu \mathrm{M}$ PCB153/PCB126 or $100 \mathrm{nM} \mathrm{E2}$ for $24 \mathrm{~h}$. Thereafter, cells were washed with PBS and lysed with passive lysis buffer. Cell lysates were subjected to luciferase activity quantification with the dual-luciferase reporter assay system (Promega, USA). Relative firefly activity was normalized and quantified relative to that of Renilla luciferase.

Animal Experiments. All experimental animals (female C57BL/6 mice, 6-8 weeks old) were purchased from Vital River Laboratories, Beijing, China, and were housed under specific pathogen-free and aseptic conditions. Hepcidin-knockout mice (Hamp1 ${ }^{-/-}$) in a C57BL/ 6 background were originally provided by Dr. Sophie Vaulont ${ }^{29}$ and Dr. Tomas Ganz ${ }^{30}$ and fed with low-dosage iron (20 ppm iron) to reduce their body iron burden. All animal experimental protocols were approved by the Animal Ethics Committee at the Research Center for Eco-Environmental Sciences, Chinese Academy of Sciences. Mice received intraperitoneal administration of PCB126 (20 or $70 \mathrm{mg} / \mathrm{kg}$ body weight) dissolved in corn oil, whereas control mice received corn oil only. Here, heparin (dissolved in PBS and given at a concentration of $8 \mathrm{mg} / \mathrm{kg}$ body weight) was used as a positive control to inhibit hepcidin expression, as previously described. ${ }^{24}$ All mice were closely observed during the experiment and were weighed before and after the administration.

Histological Analysis. Hematoxylin and eosin (H\&E) staining of liver and spleen sections was carried out as previously reported. ${ }^{31}$ Briefly, liver and spleen specimens were fixed in $4 \%$ PBS-buffered formaldehyde and then embedded in paraffin. Sections were stained with $\mathrm{H} \& \mathrm{E}$ following standard techniques. Oil red $\mathrm{O}$ staining was performed on $8 \mu \mathrm{m}$ frozen sections from liver specimens preserved in OCT medium. Sections were air-dried, fixed in $4 \%$ paraformaldehyde, and then immersed in filtered oil red O (Solarbio, Beijing, China) in $70 \%$ isopropanol for $10 \mathrm{~min}$. After rinsing in 70\% isopropanol, nuclei were stained with hematoxylin.

Iron Measurement and Staining. Serum iron was measured with a kit according to the manufacturer's instructions (Nanjing Jiancheng
Bioengineering Institute, Nanjing, China). Liver and spleen nonheme iron content was determined as previously described. ${ }^{31}$ For iron staining, sections were incubated in Prussian blue solution (Beijing Leagene Biotechnology Co., Beijing, China) to stain nonheme iron. Slides were finally counter-stained with nuclear fast red following a standard protocol.

Measurement of Glutathione Peroxidase (GSH- $\left.P_{\mathrm{X}}\right)$ and CReactive Protein (CRP). The GSH-P $\mathrm{P}_{\mathrm{X}}$ activity was determined with an enzyme activity detection kit from QnDsystems (Wuhan, China). The CRP level was assayed with a CRP ELISA kit from RayBiotech (Atlanta, GA, USA). The experiments were performed according to the corresponding protocols from the manufacturers.

Statistical Analysis. Statistical analysis was performed by an independent $t$-test or one-way ANOVA. Experimental data are shown as the mean \pm standard error. Statistical significance was determined at a $P$ value of less than 0.05 .

\section{RESULTS}

Cytotoxicity in HepG2 Cells Exposed to PCB153 and PCB126. The liver is the preferential organ for PCBs deposition due to their significant lipophilicity. ${ }^{32}$ Moreover, the liver is also the primary organ involved in controlling iron metabolism, as hepatocytes are the predominant producers of hepcidin. ${ }^{33}$ Therefore, we studied the potential disruption of iron homeostasis in response to PCB exposure by evaluating hepcidin production in hepatocytes. We first assayed cytotoxicity in HepG2 cells upon exposure to a range of concentrations of PCB153 and PCB126 using an MTT assay. As shown in Figure 1A,B, PCB126 and PCB153 at concentrations from 0.01 to $5 \mu \mathrm{M}$ did not induce cytotoxicity toward HepG2 cells, as demonstrated by the very minimal change in cell viability assessed by the MTT assay. Previous studies revealed that the levels of PCBs in human serum were up to a few micromoles. ${ }^{34}$ Thus, to better mimic the level of human exposure to PCBs, a nontoxic concentration of $1 \mu \mathrm{M}$ was used in the following experiments. To evaluate the potential damage to cells by PCBs, LDH leakage was assayed. The $\mathrm{LDH}$ release assay indicated that $\mathrm{PCB} 153$ or $\mathrm{PCB} 126$ at 1 $\mu \mathrm{M}$ had no effect on extracellular $\mathrm{LDH}$ release (Figure $1 \mathrm{C} ; \mathrm{P}>$ 
(A)

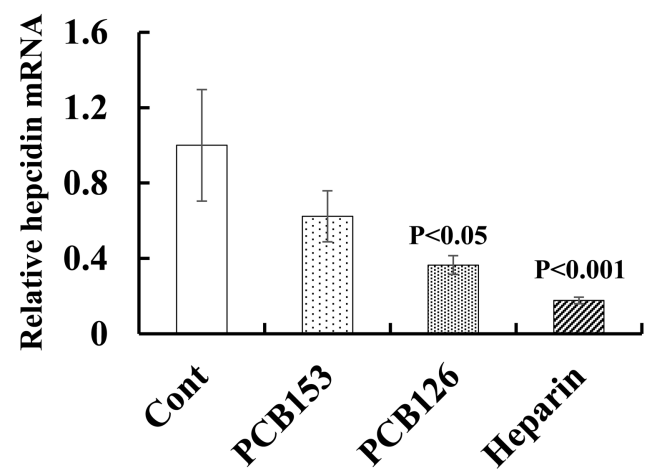

(B)

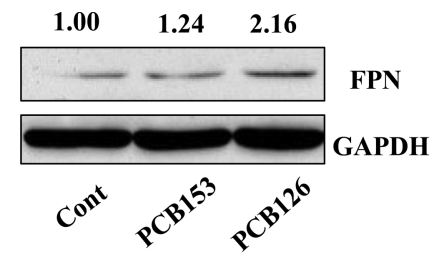

(C)

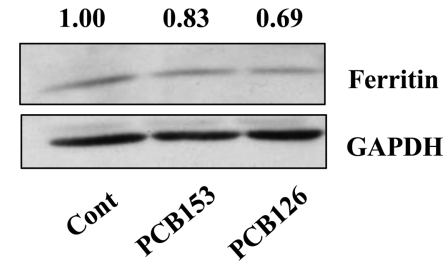

Figure 2. Regulation of hepcidin expression by PCB153 and PCB126. HepG2 cells were treated with $1 \mu \mathrm{M}$ PCB153/PCB126 for $24 \mathrm{~h}$, and then total RNA and protein were extracted. (A) Hepcidin mRNA levels were determined by qRT-PCR analysis $(n=4)$. The concentrations of (B) FPN and $(\mathrm{C})$ ferritin were assessed through western blot analysis. Heparin served as a positive control to determine the relative abundance of hepcidin mRNA.

0.05), consistent with the results of the MTT assay (Figure $1 \mathrm{~A}, \mathrm{~B})$. Here, TCDD was used as a positive control. ${ }^{35,36}$ As shown in Figure 1, TCDD at $5 \mu \mathrm{M}$ exerted significant toxicity to the cells, as reflected by the MTT and LDH assays $(P<$ $0.05)$.

Alteration of Hepcidin Expression by PCB153 and PCB126. Next, we assessed the level of hepcidin expression upon exposure to PCB153 and PCB126. As illustrated in Figure $2 \mathrm{~A}$, the mRNA levels of hepcidin were suppressed in cells treated with these chemicals at $1 \mu \mathrm{M}$ for $24 \mathrm{~h}$. The hepcidin level was reduced by $30 \%$ in cells treated with PCB153, compared to that in the untreated cells, although this was not statistically significant. Hepcidin expression was inhibited by $>50 \%$ in cells upon PCB126 treatment, relative to its expression level in the control $(P<0.05)$. Here, heparin served as a positive control to inhibit hepcidin transcription in cultured cells in vitro. ${ }^{24,37}$ As shown in Figure $2 \mathrm{~A}$, heparin at $4 \mu \mathrm{g} / \mathrm{mL}$ greatly repressed hepcidin transcription $(P<0.05)$.

FPN, the sole iron exporter, ${ }^{38}$ is specifically internalized and degraded by binding to hepcidin. ${ }^{19}$ As a consequence of hepcidin reduction upon PCB153 and PCB126 exposure, the FPN protein concentration was correspondingly increased, as reflected by western blot analysis (Figure $2 \mathrm{~B}$ ). Moreover, the increase in the FPN concentration took place in parallel to the reduction of hepcidin. Namely, the increase in the concentration of FPN in cells treated with PCB126 was greater than that in cells treated with PCB153 (Figure 2B). Upon this change in FPN, the intracellular iron level changed accordingly. Ferritin light chain was used here to reflect intracellular iron storage. As shown in Figure 2C, the ferritin concentration was reduced in cells upon PCB153 treatment and to a greater extent in cells treated with PCB126, suggesting a loss of intracellular iron content. These data thus indicated that hepcidin expression could be downregulated by PCB153 and PCB126 and that PCB126 exerted a greater inhibition on hepcidin expression than that by PCB153.

PCB126 Suppressed Hepcidin Expression in Mice. To substantiate the findings of PCB-induced inhibition of hepcidin expression in vitro described above, the in vivo effect was studied through PCB126 administration in mice. Previous studies have documented high levels of PCBs in blood in the general population. ${ }^{39}$ Moreover, due to the significant lip- ophilicity of PCBs, ${ }^{40,41}$ they tend to accumulate in fat-rich tissues (such as the liver and breast), with the local concentration being tens or even hundreds of times greater than that in blood. ${ }^{42}$ In other words, organs (e.g., liver and breast) are the preferential sites for PCB accumulation. To this end, to mimic the accumulative effect of PCBs in liver, higher concentrations (20 and $70 \mathrm{mg} / \mathrm{kg}$ body weight) were chosen, paralleling that in previous studies. ${ }^{23,43,44}$ No abnormal activity or dietary change was observed, and no body weight loss was found for mice upon PCB administration at the current doses. qRT-PCR results showed that hepatic hepcidin expression was impeded by approximately $60 \%$ in mice upon PCB 126 administration at 20 or $70 \mathrm{mg} / \mathrm{kg}$ compared to that in the untreated control mice (Figure 3A; $P<0.05$ ). Upon the reduction in hepcidin, iron in the liver and spleen was depleted by approximately 30 and 50\% in mice with PCB administration, respectively, compared to that in the control (Figure 3B,C; $P<$ 0.05 ). As a result, the level of serum iron was elevated in PCB126-treated mice relative to that in the control (Figure 3D; $P<0.05$ ). As shown in Figure 3B-D, no significant change was found in the iron content in the serum, liver, and spleen in mice administered with either 20 or $70 \mathrm{mg} / \mathrm{kg}$ PCB126 ( $P>0.05)$, suggesting that the concentration of $20 \mathrm{mg} / \mathrm{kg}$ reached a maximal inhibitory effect on hepcidin expression. To substantiate these iron changes, we stained spleen sections with Prussian blue to detect iron. As shown in Figure 3E,F, no histological impairment was observed in the spleen sections from mice administered PCB126, suggesting that no significant toxicity was induced to the spleen by PCB126. Nonheme iron staining (shown in blue) of spleen sections showed that iron was mainly present in macrophages (Figure 3G,H), and a significant decrease of nonheme iron was found in spleen sections from mice treated with PCB126 compared to that from untreated mice (Figure 3G,H), analogous to the quantification results (Figure 3C). Heparin was used here as a positive control to repress hepcidin expression in mice. Analogous to the data reported in our recent paper, ${ }^{24}$ heparin (at $8 \mathrm{mg} / \mathrm{kg}$ body weight) was demonstrated to greatly suppress hepcidin expression, which was coupled with corresponding changes in serum and tissue iron (Figure 3A$\mathrm{D} ; P<0.05)$. All together, these observations suggested that 


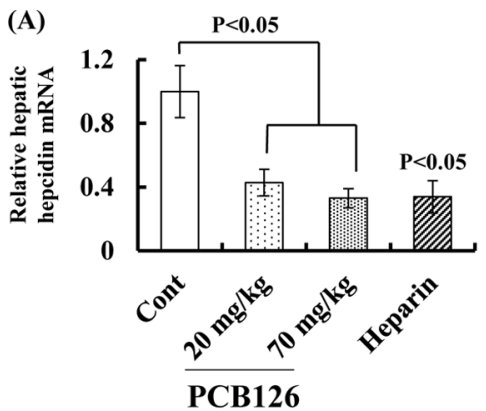

(B)

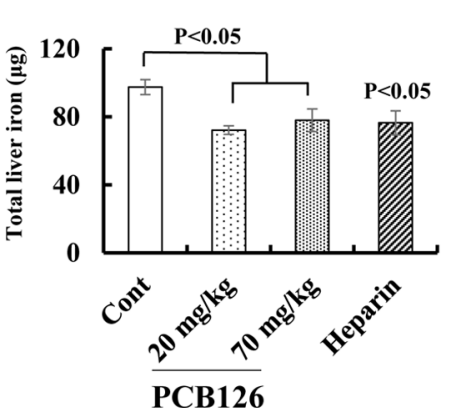

(C)

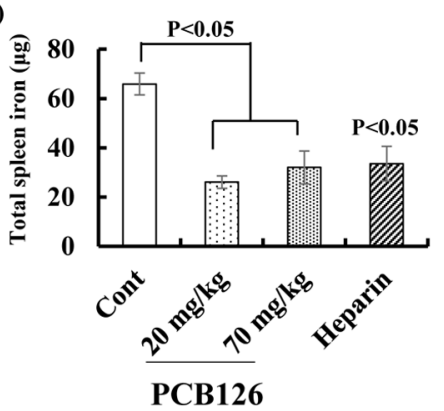

(D)

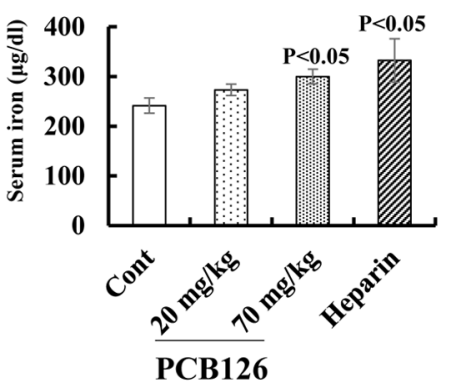

(E)
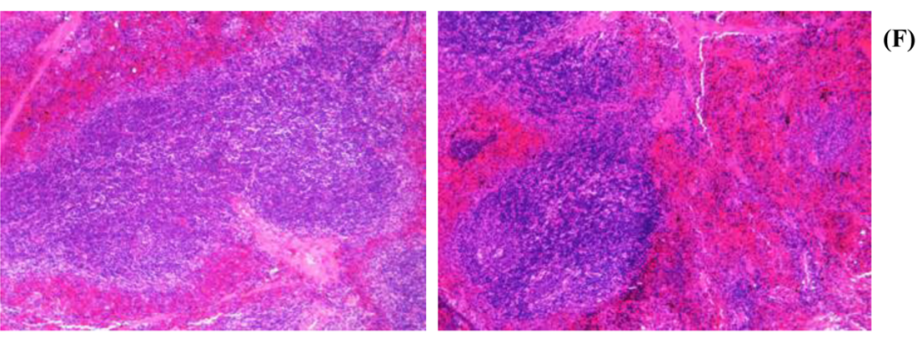

(G)
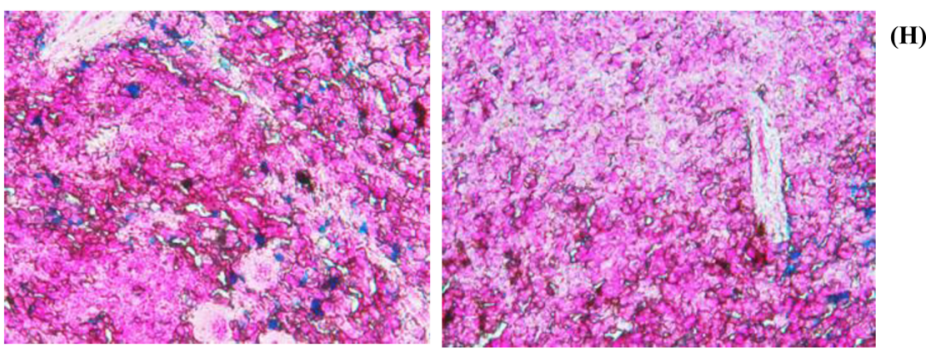

Cont

PCB126

Figure 3. Effects of PCB126 on iron homeostasis in mice. Female mice in the C57BL/6 genetic background were intraperitoneally administered PCB126 (20 or $70 \mathrm{mg} / \mathrm{kg}$ body weight). Mice were sacrificed after administration for $48 \mathrm{~h}$, and (A) hepatic hepcidin mRNA, (B) total liver iron, (C) total spleen iron, and (D) serum iron were assayed $(n=7)$. Representative images show spleen sections after H\&E staining from (E) untreated mice and (F) PCB126-treated mice $(20 \mathrm{mg} / \mathrm{kg})$. Magnification, $\times 100$. Prussian blue staining for iron was also performed on spleen sections from $(\mathrm{G})$ untreated mice and (H) PCB126-treated mice $(20 \mathrm{mg} / \mathrm{kg})$. Blue dots denote iron stained in the spleen sections. Magnification, $\times 400$. Heparin serves as a positive control for assessing hepatic hepcidin expression and serum and tissue iron concentrations.

PCB126 restrained hepcidin expression in mice, leading to disordered systemic iron homeostasis.

PCB126 Caused Lipid Accumulation in Liver. In addition, hepatomegaly was observed in mice treated with PCB126, as the ratio of liver weight to body weight was increased by approximately $25 \%$ in mice treated with PCB126 at 20 or $70 \mathrm{mg} / \mathrm{kg}$ body weight compared to that of the untreated mice (Figure 4A; $P<0.05$ ). To evaluate possible hepatic injury induced by $\mathrm{PCB} 126$, we examined liver sections using H\&E staining. As shown in Figure 4B,C, there was no clear evidence of hepatic injury in PCB126-treated mice. However, hepatocytes were visualized with large vacuolation in sections from mice upon PCB126 exposure but not in those from the untreated mice (Figure 4B,C). On the basis of previous studies, ${ }^{32,33}$ we hypothesized that this vacuolation around hepatocytes was likely the formation of lipid droplets. To test this idea, oil red $\mathrm{O}$ staining of liver sections was carried out to stain lipids. The staining results indicated that remarkable lipid accumulation (in red) occurred in the livers of PCB126-administered mice but not in the livers from untreated mice (Figure 4D,E). This observation was similar to a recent study that showed significant formation of fatty liver in mice upon exposure to PCBs. ${ }^{45}$

PCB126 Did Not Alter Iron Homeostasis in HepcidinDeficient Mice. In attempt to further verify the inhibitory effect of PCB126 on hepcidin, hepcidin-knockout (Hamp1 ${ }^{-/-}$) mice were chosen as an experimental model. Hamp $1^{-/-}$mice were administered $20 \mathrm{mg} / \mathrm{kg}$ PCB126 and were sacrificed $48 \mathrm{~h}$ 
(A)
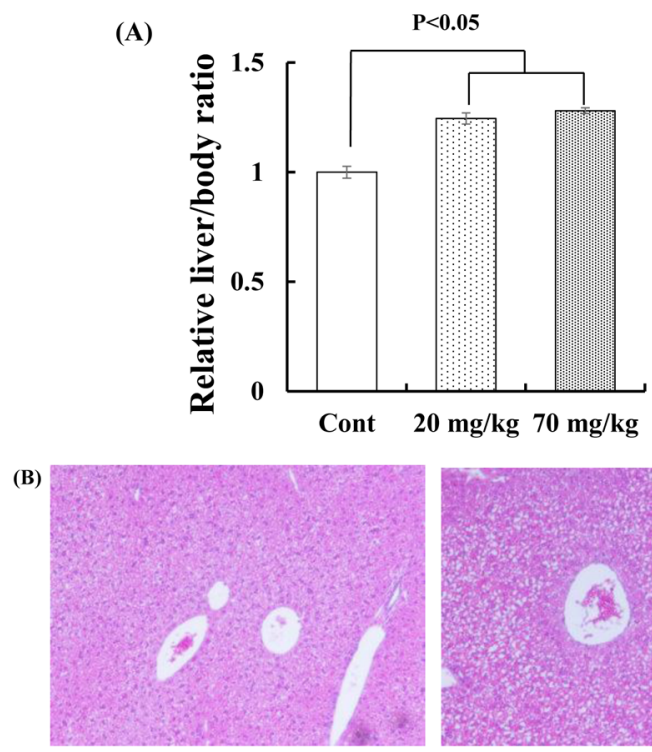

(D)

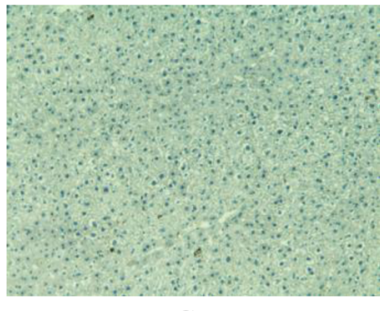

Cont

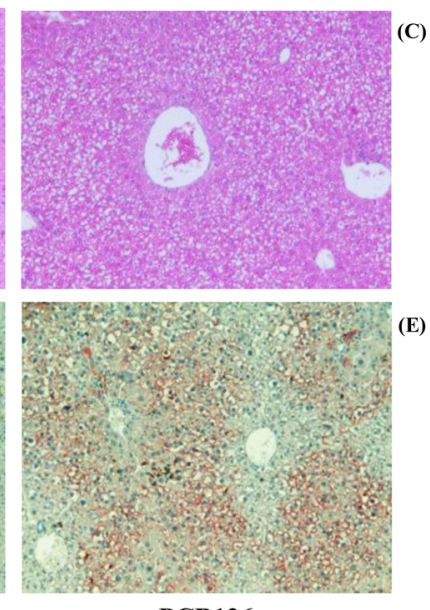

PCB126

Figure 4. Lipid accumulation induced by PCB126 in mice. (A) Relative liver weight ratio normalized to body weight. (B, C) H\&E staining of liver sections from untreated and PCB126-treated mice. (D, E) Oil red $\mathrm{O}$ staining of liver sections from control and PCB126treated mice. Mice were treated with $20 \mathrm{mg} / \mathrm{kg}$ PCB126 for $48 \mathrm{~h}$. Magnification, $\times 100$.

later. The content of serum iron, hepatic iron, and spleen iron was not significantly altered in Hamp1 ${ }^{-/-}$mice after PCB126 administration compared to that in the untreated control mice (Figure 5A-C; $P>0.05$ ). The ratio of liver to body weight was not significantly altered in Hamp1 $1^{-/-}$mice post PCB126 administration (Figure 5D), in contrast to a significant change observed in wild-type (WT) mice (Figure 4A). Additionally, we studied the histology of sections of liver specimens from Hamp $1^{-/-}$mice post PCB126 treatment. No significant damage was observed in these liver sections, in agreement with the observation in WT mice (Figure 4B,C). Importantly, lipid accumulation was observed in mice under hepcidin deficiency with or without PCB126 treatment (Figure 5G,H). These data suggested an important crosstalk between iron metabolism and lipid metabolism in liver. ${ }^{46}$ Moreover, the lipid accumulation phenotype appeared to be more severe in $\mathrm{Hamp1}^{-/-}$mice after PCB126 treatment compared to that in the untreated mice (Figure 5G,H), consistent with the findings in WT mice (Figure 4D,E). These results together suggested that the removal of PCB126-mediated suppression of hepcidin failed to affect systemic iron homeostasis and that PCB126 administration resulted in increased lipid accumulation in the liver in both WT and hepcidin-deficient mice.

Hepcidin Transcription Was Regulated by PCBs through an ERE within the Hepcidin Promoter. We next aimed to elucidate the molecular mechanisms responsible for the suppression of hepcidin by PCBs. A number of studies

have proposed that PCBs are potential environmental endocrine disruptors that bind to ERs. ${ }^{4-49}$ Our research group recently discovered a functional ERE within the hepcidin promoter and demonstrated an inhibitory effect of estrogen on hepcidin transcription. ${ }^{28}$ The above findings for PCB153 and PCB126 indicated that the inhibitory effect on hepcidin was likely associated with the xenoestrogenic activity of these chemicals. First, to substantiate the role of estrogen in regulating hepcidin expression, we assessed the endogenous expression of hepcidin in HepG2 cells in response to E2. 17 $\beta$ Estradiol at $100 \mathrm{nM}$ significantly inhibited endogenous hepcidin mRNA expression by nearly $30 \%$ (Figure 6A; $P<$ 0.05 ), and this inhibition could be reversed by $1 \mu \mathrm{M}$ tamoxifen (Figure 6A; $P<0.05$ ), an estrogen antagonist that bind to $\mathrm{ER}^{50}$ These data verified the important role of estrogen in repressing hepcidin transcription through an ER-dependent signaling pathway.

Because many PCB congeners harbor estrogenic activity, we then determined this property for PCB153 and PCB126 with an established assay of estrogen activity, i.e., the luciferase reporter plasmid pERE-AUG-Luc+. ${ }^{26,27}$ As shown in Figure 6B, luciferase activity was elevated by almost $20 \%$ in response to PCB153 $(P<0.05)$ and was further augmented by approximately $30 \%$ upon exposure to PCB126 $(P<0.05)$ relative to that in the untreated control. $17 \beta$-Estradiol was used as a positive control (Figure 6B; $P<0.05$ ). These results indicated that both PCB126 and PCB153 demonstrated an estrogen-like property, and $\mathrm{PCB} 126$ possessed greater estrogenic activity than did PCB153, consistent with the findings from a previous study. ${ }^{51}$ On the basis of the above data, we assumed that PCB153 and PCB126 suppressed hepcidin expression in a manner that was dependent on ER signaling. To test this hypothesis, we transfected HepG2 cells with two luciferase reporter constructs, i.e., containing the hepcidin promoter with or without the ERE (pro + ERE vs pro $\Delta$ ERE, respectively). The luciferase activity of pro + ERE was reduced upon PCB153 treatment, although this was devoid of statistical significance, and the luciferase activity in response to PCB126 was further reduced by approximately $20 \%$ compared to that in the untreated cells (Figure 6C; $P<0.05$ ). The further reduction of the pro + ERE luciferase activity for PCB126 relative to PCB153 was in agreement with their distinct estrogenic properties, as described in Figure 6B. However, the changes induced by PCB153 and PCB126 were completely eliminated when the ERE was removed from the hepcidin promoter, as PCB153 and PCB126 treatment did not influence the luciferase activity in cells transfected with the hepcidin promoter without the ERE (namely, pro $\Delta$ ERE) (Figure 6D; $P>0.05$ ). $17 \beta$ Estradiol was also used here as a control (Figure 6C,D). All together, these results identified the ERE within the hepcidin promoter as the molecular basis for the repression of hepcidin expression in response to PCBs. Moreover, our data suggested that the lower level of hepcidin suppression mediated by PCB153 compared to that by PCB126 was due to the weaker estrogenic activity of PCB153 relative to that of PCB126.

Effects of PCBs on Oxidative Stress, Inflammatory Reaction, and BMP-6. In addition to the estrogenic activity of PCBs, we also searched for other possible mechanisms that could be involved in PCB-mediated inhibition of hepcidin. Previous studies have demonstrated that production of ROS ${ }^{52}$ and inflammation ${ }^{19}$ can affect hepcidin expression. Meanwhile, PCBs at higher concentrations might be able to trigger ROS and inflammation in certain cells. ${ }^{5,54}$ Thus, we asked whether 
(A)

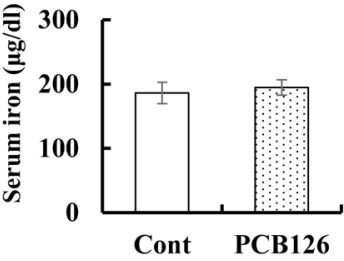

(C)

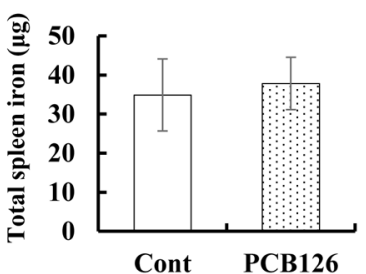

(E)

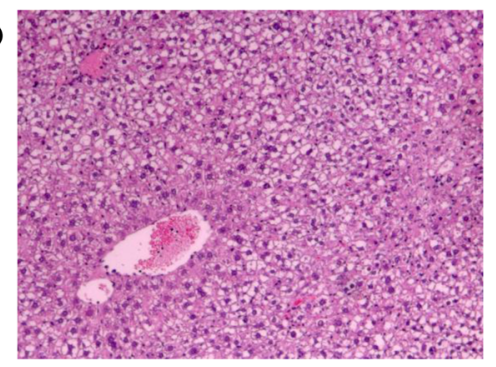

(G)

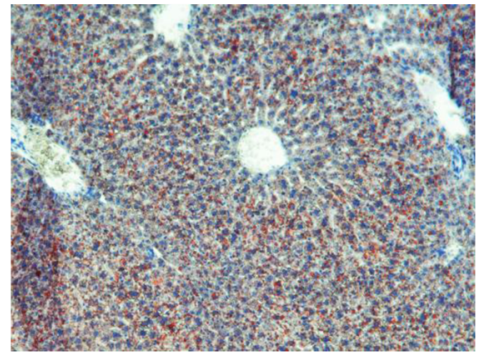

Cont
(B)

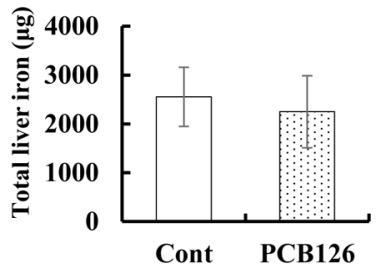

(D)
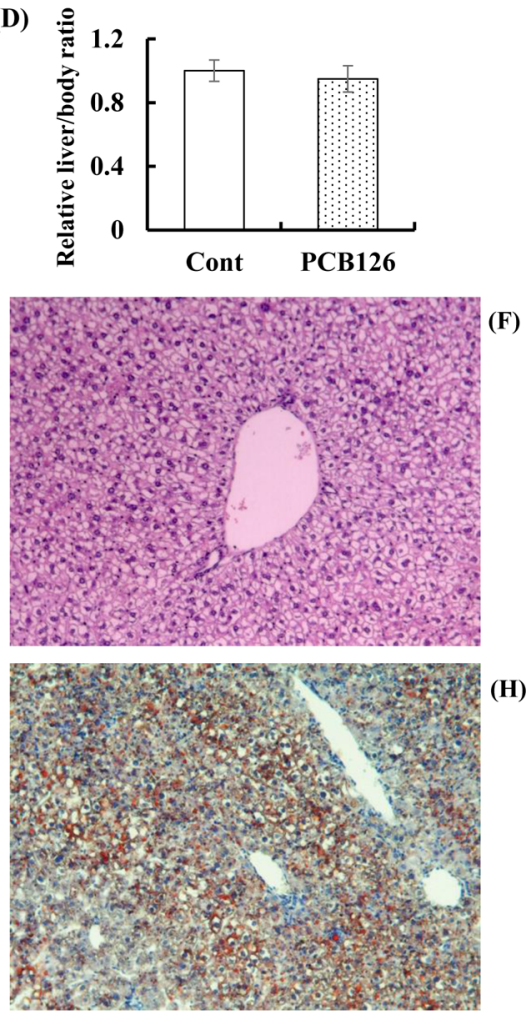

PCB126

Figure 5. Iron and lipid homeostasis in $\mathrm{Hamp1}^{-/-}$mice upon $\mathrm{PCB} 126$ administration. Female Hamp1 $1^{-/-}$mice were administered $20 \mathrm{mg} / \mathrm{kg}$ PCB126 for $48 \mathrm{~h}$, similar to that using WT mice described in Figure 3. Mice were then sacrificed. (A) Serum iron, (B) total liver iron, (C) total spleen iron, and (D) relative liver/body weight ratio were determined $(n=7)$. H\&E $(\mathrm{E}, \mathrm{F})$ and oil red $\mathrm{O}(\mathrm{G}, \mathrm{H})$ staining of liver sections was performed. (E, G) Untreated mice; (F, H) mice treated with $20 \mathrm{mg} / \mathrm{kg}$ PCB126. Magnification, $\times 100$.

oxidative stress or inflammation could be implicated in regulating hepcidin in response to PCB153 and PCB126. To test this possibility, we investigated the production of ROS and inflammation in HepG2 cells after treatment with these chemicals at $1 \mu \mathrm{M}$ for 1,2 , and $24 \mathrm{~h}$. As shown in Figure $7 \mathrm{~A}$, the level of ROS barely changed in response to the treatments at different time points. $\mathrm{H}_{2} \mathrm{O}_{2}$ was used as a positive control to measure the production of ROS. Meanwhile, the activity of an antioxidant enzyme, GSH- $\mathrm{P}_{\mathrm{X}}$, ${ }^{55}$ was not significantly changed in cells upon treatment with these chemicals (Figure 7B). With respect to the inflammatory response, the production of CRP and expression of IL-6 were assessed. As shown in Figure 7C,D, the levels of CRP and IL-6 remained consistent in cells after treatment with these compounds. These observations thus ruled out oxidative stress and IL-6 signaling as playing a part in the regulation of hepcidin by PCB126 and PCB153. Additionally, since BMP-6 is also a fundamental regulator of hepcidin expression in hepatocytes, $^{24,56,57}$ we measured the mRNA level of BMP-6 in HepG2 cells in the presence of PCB126 or PCB153 for $24 \mathrm{~h}$. The level of BMP- 6 expression was scarcely altered by the treatments (Figure 7E), precluding the involvement of BMP-6 in regulating hepcidin expression upon exposure to PCBs.
These data collectively revealed that PCBs at the current concentrations did not elicit oxidative stress or inflammatory reactions and also suggested that the inhibition of hepcidin by PCBs was independent of oxidative stress, inflammation, and BMP-6 in HepG2 cells.

\section{DISCUSSION}

PCBs, a large family of persistent organic pollutants, ${ }^{58}$ can accumulate readily in fat-rich tissues, such as adipose, breast, and liver, ${ }^{59}$ and the level of PCBs detected in fat-rich tissues is likely 30-500-fold higher than that detected in blood. ${ }^{42}$ The liver plays a prominent role in regulating systemic iron homeostasis, as liver-secreted hepcidin fundamentally governs dietary iron absorption and iron egress from macrophages. However, whether PCB accumulation can disturb iron homeostasis has not been investigated. To date, the regulation of hepcidin expression has been primarily governed by BMPSmad1/5/8 signaling, Stat 3 inflammatory signaling, and erythroid factors. ${ }^{18,60,81}$ In addition to these signaling pathways, we recently demonstrated that estrogen-mediated signaling is also involved in hepcidin regulation, with estrogen repressing hepcidin expression through a functional ERE within the hepcidin promoter. ${ }^{28}$ Moreover, our recent study indicated that 
(A)

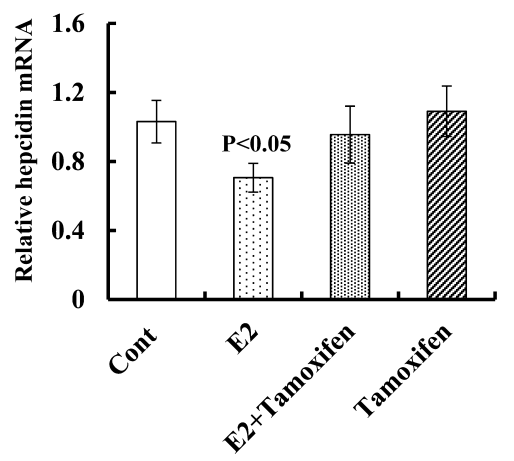

(C)

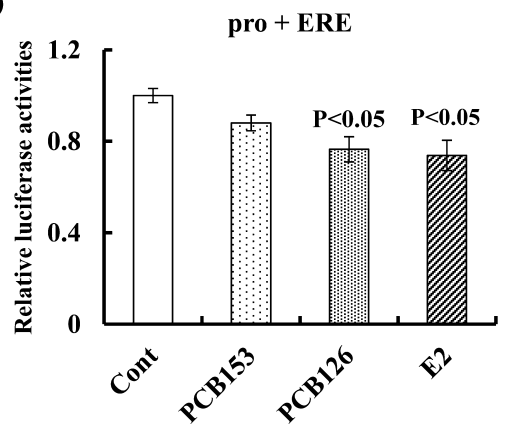

(B)

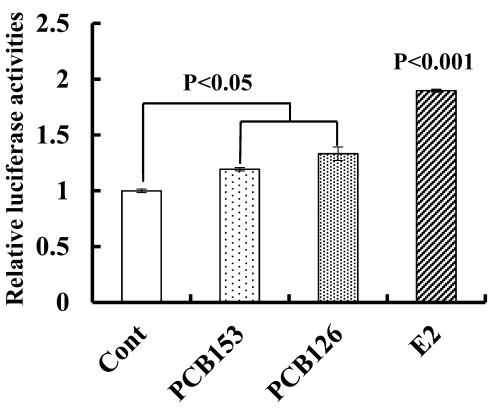

(D)

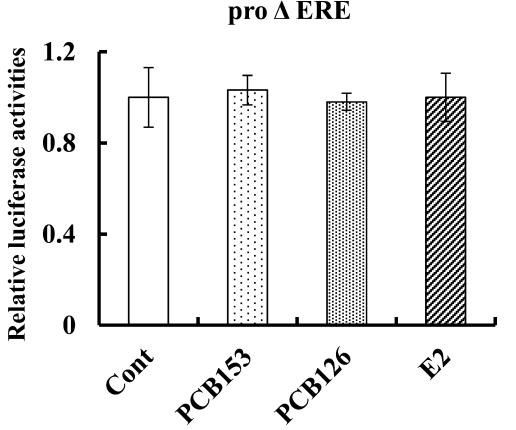

Figure 6. Relative estrogenic activity of PCBs. (A) The mRNA level of hepcidin in HepG2 cells upon treatment with 17 $\beta$-estradiol and/or tamoxifen for $24 \mathrm{~h}$. (B) pERE-AUG-Luc+ and $\mathrm{rER} \alpha / \mathrm{pCI}$ plasmids, (C) the pGL3-based plasmid including the hepcidin promoter with the ERE (pro + ERE), and (D) the pGL3-based plasmid containing the hepcidin promoter without the ERE (pro $\triangle$ ERE) were cotransfected with a Renilla luciferase plasmid into HepG2 cells. Luciferase activity was detected after PCB153, PCB126, or E2 treatment for 24 h. Relative luciferase activity was quantified by normalization to that of Renilla luciferase.

a PCB congener, PCB77, could disturb systemic iron homeostasis through repressing hepcidin expression. ${ }^{23}$ These findings collectively inspired us to postulate that PCBs could modulate hepcidin expression through their estrogen-like property.

Regarding the estrogenic activity of PCBs, the current literature provides a lot of information; however, it has to be noted that there are still inconsistent and even conflicting results among the different reports, possibly due to different concentrations, tools, measurements, and cell and animal models used. For example, and analogous with our current findings, a previous study from $\mathrm{Li}$ et al. also demonstrated that PCB153 exhibits estrogenic effects in rat. ${ }^{62}$ Similarly, Desaulniers et al. also documented the estrogen-like activity of PCB153 by affecting thyroxin levels in vivo. ${ }^{63}$ However, other studies reported a weak anti-estrogenic activity of PCB153, ${ }^{13,14}$ where discrepant concentrations and cell types were employed. Therefore, these discrepancies warrant further detailed investigations. In the current study, we verified estrogen-like activity for both PCB126 and PCB153, in support of previous reports. ${ }^{10,23,64,65} \mathrm{We}$ also discovered that PCB126 exerted a stronger estrogenic activity than that of PCB153 in HepG2 cells. Importantly, we demonstrated that PCB153 and PCB126 significantly inhibited hepatic hepcidin expression through ERdependent signaling, independent of oxidative stress, BMP-6, and IL-6. PCB-induced inhibition of hepcidin resulted in corresponding changes in systemic iron homeostasis, as reflected by alterations in serum and tissue iron concentrations. However, hepcidin deficiency endowed mice with resistance to the iron-based effects of treatment with PCBs, as no changes in iron status were found in Hamp $1^{-/-}$mice administered PCBs. At the molecular level, PCBs were demonstrated to repress hepcidin expression through an ERE within the hepcidin promoter. PCB126 was revealed to have a greater capability to restrain hepcidin transcription than that of $\mathrm{PCB} 153$, in agreement with the stronger estrogenic activity of PCB126 relative to that of PCB153.

Iron metabolism and lipid metabolism are intertwined, as deregulated iron metabolism is often coupled to disordered lipid hemostasis. ${ }^{46,66,67}$ An increased iron load results in disordered lipid metabolism, associated with ungoverned lipogenesis in the liver. ${ }^{68,69}$ For example, hepatic fatty acids in the presence of iron overload exhibited an inhibitory effect on lipogenic genes (e.g., fatty acid synthase) by exerting a preoxidative cytotoxic effect. ${ }^{70}$ We here found that hepatocytes were vacuolated and lipid-accumulated in mice upon PCB126 exposure, indicating that $\mathrm{PCBs}$ exerted detrimental effects on both of these metabolic pathways in the liver. We also observed significant lipid accumulation in hepcidin-deficient mice, irrespective of PCB exposure. However, the crosstalk is rather complex among iron metabolism, lipid metabolism, and PCB's preferential hepatic deposition, and further detailed investigations are warranted.

Estrogen is an indispensable hormone for the development of the reproductive system and the maintenance of the physiological functions of organs in females. However, ERs are often overexpressed in breast cancer, with approximately $70 \%$ of invasive breast cancers having this feature. ${ }^{71}$ Binding to their receptors promotes both genomic and nongenomic effects, leading to aggressive growth and progression of breast cancer cells. $^{72,73}$ Meanwhile, accumulating evidence suggests that disordered iron metabolism increases the risk of tumor initiation and metastasis for breast cancer and other cancer types through various mechanisms including overproduction of 
(A)

(D)
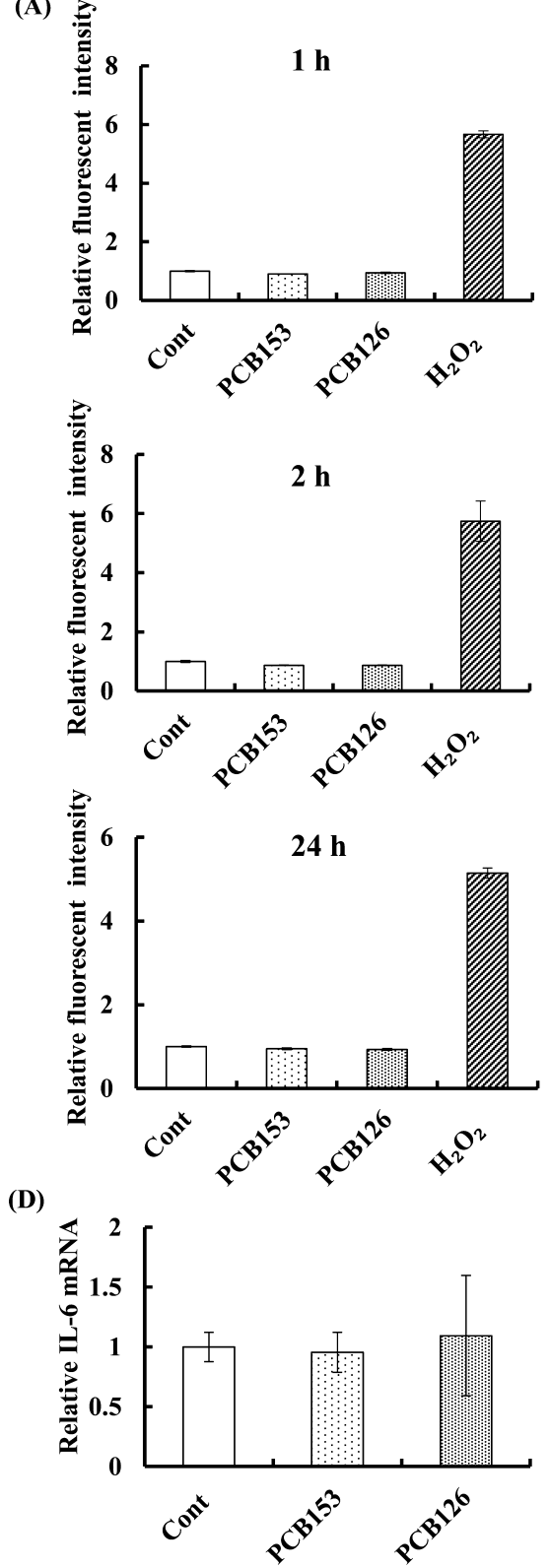

(B)

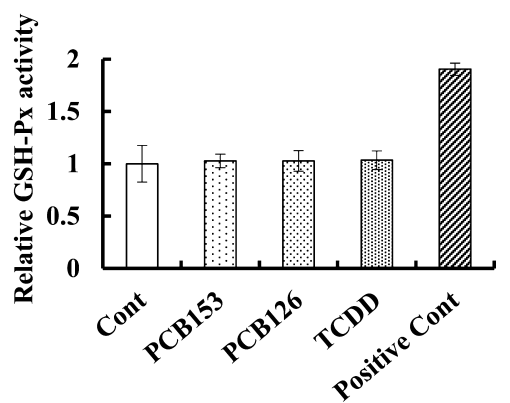

(C)

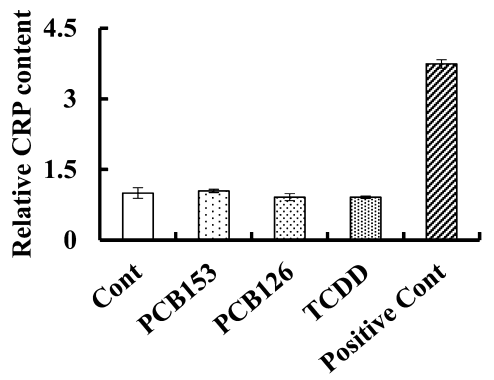

(E)

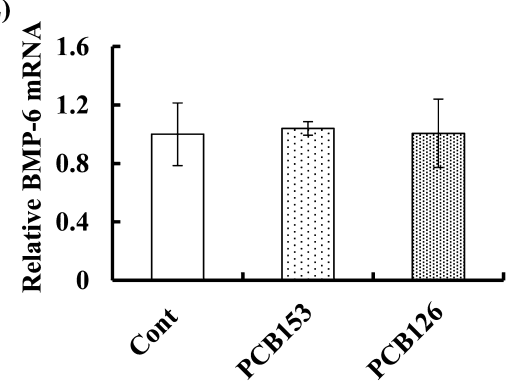

Figure 7. Effects of PCB153 and PCB126 on oxidative stress, inflammation, and BMP-6 expression. (A) ROS levels were detected in HepG2 cells after $1 \mu \mathrm{M} \mathrm{PCB} 153 / \mathrm{PCB} 126$ treatment for 1,2 , and $24 \mathrm{~h}(n=6) \cdot \mathrm{H}_{2} \mathrm{O}_{2}$ at $0.1 \%$ served as a positive control. GSH-P $(\mathrm{B})$ and CRP (C) were measured in HepG2 cells after PCB126/PCB153 treatment at $1 \mu \mathrm{M}$ for $24(n=3)$. For GSH and CRP, we used positive controls in the kits provided by the manufacturers. The mRNA level of (D) IL-6 and (E) BMP-6 was determined in HepG2 cells after a 24 h treatment with PCB126 or PCB153 at $1 \mu \mathrm{M}$ by qRT-PCR analysis $(n=4)$.

free radicals. ${ }^{74,75}$ Additionally, iron also contributes to breast cancer through interacting with estrogen. For example, our recent findings demonstrated that estrogen regulates iron homeostasis through modulating hepcidin transcription via an ERE in the promoter of hepcidin gene. ${ }^{28}$ Therefore, the current study recognized a significant role of PCBs in modulating iron metabolism through their estrogen-like property and highlighted the important interface between estrogen and iron. This work interconnects the functions and signaling between estrogen and iron upon PCB exposure. To this end, our combined findings have revealed more insight into the mechanisms responsible for PCB-induced tumor-modulating effects (such as breast cancer) from the perspective of altered iron metabolism, which is affected by their estrogen-like effects.
To summarize, PCB126 and PCB153 exhibited a pronounced ability to inhibit hepatic hepcidin expression. Mechanistic studies suggested that PCB-mediated downregulation of hepcidin was dependent on their estrogen-like effects in hepatocytes. In support of this mechanism, PCB126 revealed a greater ability to suppress hepcidin than that of PCB153, as PCB126 exhibited greater estrogenic activity than PCB153. In vivo administration of PCB126 gave rise to disordered systemic iron homeostasis, as reflected by altered iron content in serum and organs. Disordered lipid metabolism was also observed in mice upon PCB126 exposure, as evidenced by lipid accumulation in liver. All together, our findings not only signified a novel toxicity feature for PCBs in disturbing systemic iron homeostasis by regulating ERdependent hepcidin expression but also implied a significant 
role of iron in a variety of disorders (such as cancer progression) under the setting of PCB exposure.

\section{AUTHOR INFORMATION}

\section{Corresponding Authors}

*(M.Z.) E-mail: zhaomr@zjut.edu.cn.

*(S.L.) E-mail: sjliu@rcees.ac.cn. Tel./Fax: 8610-62849330.

\section{Funding}

This work was supported by grants under the national "973" program (grant no. 2014CB932000), the Strategic Priority Research Program of the Chinese Academy of Sciences (grant no. XDB14000000), and the National Natural Science Foundation of China (grant nos. 21377159, 21177151, and 21321004).

\section{Notes}

The authors declare no competing financial interest.

\section{ACKNOWLEDGMENTS}

We thank Drs. Sophie Vaulont and Tomas Ganz for their generous provision of Hamp1 $1^{-/-}$mice. We thank Dr. Ming Gao and Jing Liu for their critical reading of the manuscript. We thank all of the members laboratory for their great assistance with experiments and reagents.

\section{ABBREVIATIONS}

PCBs, polychlorinated biphenyls; FPN, ferroportin; ERE, estrogen response element; $\mathrm{ER} \alpha$, estrogen receptor $\alpha$; E2, $17 \beta$-estradiol; LDH, lactate dehydrogenase; Hamp $1^{-/-}$, hepcidin-knockout mice; H\&E, hematoxylin and eosin; GSH$\mathrm{P}_{\mathrm{X}}$, glutathione peroxidase; $\mathrm{CRP}, \mathrm{C}$-reactive protein

\section{REFERENCES}

(1) Safe, S. H. (1994) Polychlorinated-biphenyls (Pcbs): environmental impact, biochemical and toxic responses, and implications for risk assessment. Crit. Rev. Toxicol. 24, 87-149.

(2) Ward, M. P., Jablonski, C., Semel, B., and Soucek, D. (2010) The biological pathway and effect of PCBs on common terns in Lake Michigan. Ecotoxicology 19, 1513-1522.

(3) Patterson, D. G., Jr., Turner, W. E., Caudill, S. P., and Needham, L. L. (2008) Total TEQ reference range (PCDDs, PCDFs, cPCBs, mono-PCBs) for the US population 2001-2002. Chemosphere 73, S261-277.

(4) Foster, W. G. (1995) The reproductive toxicology of Great Lakes contaminants. Environ. Health Perspect. 103, 63-69.

(5) Gregoraszczuk, E. L., Grochowalski, A., Chrzaszcz, R., and Wegiel, M. (2003) Congener-specific accumulation of polychlorinated biphenyls in ovarian follicular wall follows repeated exposure to $\mathrm{PCB}$ 126 and PCB 153. Comparison of tissue levels of PCB and biological changes. Chemosphere 50, 481-488.

(6) Wang, S. L., Chang, Y. C., Chao, H. R., Li, C. M., Li, L. A., Lin, L. Y., and Papke, O. (2006) Body burdens of polychlorinated dibenzo-pdioxins, dibenzofurans, and biphenyls and their relations to estrogen metabolism in pregnant women. Environ. Health Perspect. 114, 740745.

(7) Cogliano, V. J. (1998) Assessing the cancer risk from environmental PCBs. Environ. Health Perspect. 106, 317-323.

(8) Sumpter, J. P. (1998) Xenoendorine disrupters-environmental impacts. Toxicol. Lett. 102-103, 337-342.

(9) Matthews, J., Wihlen, B., Heldring, N., MacPherson, L., Helguero, L., Treuter, E., Haldosen, L. A., and Gustafsson, J. A. (2007) Co-planar $3,3^{\prime}, 4,4^{\prime}, 5$-pentachlorinated biphenyl and non-co-planar 2,2',4,6,6'pentachlorinated biphenyl differentially induce recruitment of oestrogen receptor alpha to aryl hydrocarbon receptor target genes. Biochem. J. 406, 343-353.
(10) Abdelrahim, M., Ariazi, E., Kim, K., Khan, S., Barhoumi, R., Burghardt, R., Liu, S., Hill, D., Finnell, R, Wlodarczyk, B., Jordan, V. C., and Safe, S. (2006) 3-Methylcholanthrene and other aryl hydrocarbon receptor agonists directly activate estrogen receptor alpha. Cancer Res. 66, 2459-2467.

(11) Gjernes, M. H., Schlenk, D., and Arukwe, A. (2012) Estrogen receptor-hijacking by dioxin-like 3,3'4,4',5-pentachlorobiphenyl (PCB126) in salmon hepatocytes involves both receptor activation and receptor protein stability. Aquat. Toxicol. 124-125, 197-208.

(12) Felty, Q. (2011) Proteomic 2D DIGE profiling of human vascular endothelial cells exposed to environmentally relevant concentration of endocrine disruptor PCB153 and physiological concentration of 17beta-estradiol. Cell Biol. Toxicol. 27, 49-68.

(13) Hamers, T., Kamstra, J. H., Cenijn, P. H., Pencikova, K., Palkova, L., Simeckova, P., Vondracek, J., Andersson, P. L., Stenberg, M., and Machala, M. (2011) In vitro toxicity profiling of ultrapure non-dioxin-like polychlorinated biphenyl congeners and their relative toxic contribution to PCB mixtures in humans. Toxicol. Sci. 121, 88100

(14) Pliskova, M., Vondracek, J., Canton, R. F., Nera, J., Kocan, A., Petrik, J., Trnovec, T., Sanderson, T., van den Berg, M., and Machala, M. (2005) Impact of polychlorinated biphenyls contamination on estrogenic activity in human male serum. Environ. Health Perspect. 113, $1277-1284$.

(15) Sheftel, A., Stehling, O., and Lill, R. (2010) Iron-sulfur proteins in health and disease. Trends Endocrinol. Metab. 21, 302-314.

(16) Gozzelino, R., Jeney, V., and Soares, M. P. (2010) Mechanisms of cell protection by heme oxygenase-1. Annu. Rev. Pharmacol. Toxicol. 50, 323-354.

(17) Toxqui, L., De Piero, A., Courtois, V., Bastida, S., SanchezMuniz, F. J., and Vaquero, M. P. (2010) [Iron deficiency and overload. Implications in oxidative stress and cardiovascular health]. Nutr. Hosp. $25,350-365$.

(18) Ganz, T., and Nemeth, E. (2011) Hepcidin and disorders of iron metabolism. Annu. Rev. Med. 62, 347-360.

(19) Evstatiev, R., and Gasche, C. (2012) Iron sensing and signalling. Gut 61, 933-952.

(20) Nemeth, E., Tuttle, M. S., Powelson, J., Vaughn, M. B., Donovan, A., Ward, D. M., Ganz, T., and Kaplan, J. (2004) Hepcidin regulates cellular iron efflux by binding to ferroportin and inducing its internalization. Science 306, 2090-2093.

(21) Roy, C. N., Mak, H. H., Akpan, I., Losyev, G., Zurakowski, D., and Andrews, N. C. (2007) Hepcidin antimicrobial peptide transgenic mice exhibit features of the anemia of inflammation. Blood 109, 40384044.

(22) Ganz, T., and Nemeth, E. (2012) Hepcidin and iron homeostasis. Biochim. Biophys. Acta 1823, 1434-1443.

(23) Wang, L., Zhang, S., Lin, R., Li, L., Zhang, D., Li, X., and Liu, S. (2013) PCB-77 disturbs iron homeostasis through regulating hepcidin gene expression. Gene 532, 146-151.

(24) Zhang, S., Chen, Y., Guo, W., Yuan, L., Zhang, D., Xu, Y., Nemeth, E., Ganz, T., and Liu, S. (2014) Disordered hepcidinferroportin signaling promotes breast cancer growth. Cell. Signalling $26,2539-2550$.

(25) Qu, G., Zhang, C., Yuan, L., He, J., Wang, Z., Wang, L., Liu, S., and Jiang, G. (2012) Quantum dots impair macrophagic morphology and the ability of phagocytosis by inhibiting the Rho-associated kinase signaling. Nanoscale 4, 2239-2244.

(26) Takeyoshi, M., Yamasaki, K., Sawaki, M., Nakai, M., Noda, S., and Takatsuki, M. (2002) The efficacy of endocrine disruptor screening tests in detecting anti-estrogenic effects downstream of receptor-ligand interactions. Toxicol. Lett. 126, 91-98.

(27) Zhang, Q., Lu, M., Wang, C., Du, J., Zhou, P., and Zhao, M. (2014) Characterization of estrogen receptor alpha activities in polychlorinated biphenyls by in vitro dual-luciferase reporter gene assay. Environ. Pollut. 189, 169-175.

(28) Hou, Y., Zhang, S., Wang, L., Li, J., Qu, G., He, J., Rong, H., Ji, H., and Liu, S. (2012) Estrogen regulates iron homeostasis through 
governing hepatic hepcidin expression via an estrogen response element. Gene 511, 398-403.

(29) Viatte, L., Lesbordes-Brion, J. C., Lou, D. Q., Bennoun, M., Nicolas, G., Kahn, A., Canonne-Hergaux, F., and Vaulont, S. (2005) Deregulation of proteins involved in iron metabolism in hepcidindeficient mice. Blood 105, 4861-4864.

(30) Ramos, E., Ruchala, P., Goodnough, J. B., Kautz, L., Preza, G. C., Nemeth, E., and Ganz, T. (2012) Minihepcidins prevent iron overload in a hepcidin-deficient mouse model of severe hemochromatosis. Blood 120, 3829-3836.

(31) Liu, S., Suragani, R. N., Wang, F., Han, A., Zhao, W., Andrews, N. C., and Chen, J. J. (2007) The function of heme-regulated eIF2alpha kinase in murine iron homeostasis and macrophage maturation. J. Clin. Invest. 117, 3296-3305.

(32) Birnbaum, L. S. (1985) The role of structure in the disposition of halogenated aromatic xenobiotics. Environ. Health Perspect. 61, 1120.

(33) Ramos, E., Kautz, L., Rodriguez, R., Hansen, M., Gabayan, V., Ginzburg, Y., Roth, M. P., Nemeth, E., and Ganz, T. (2011) Evidence for distinct pathways of hepcidin regulation by acute and chronic iron loading in mice. Hepatology 53, 1333-1341.

(34) Hansen, L. G., DeCaprio, A. P., and Nisbet, I. C. T. (2003) PCB congener comparisons reveal exposure histories for residents of Anniston, Alabama, USA. Fresenius Environ. Bull. 12, 181-190.

(35) Aly, H. A., and Domenech, O. (2009) Cytotoxicity and mitochondrial dysfunction of 2,3,7,8-tetrachlorodibenzo- $p$-dioxin (TCDD) in isolated rat hepatocytes. Toxicol. Lett. 191, 79-87.

(36) Aly, H. A., and Khafagy, R. M. (2011) 2,3,7,8-Tetrachlorodibenzo-p-dioxin (TCDD)-induced cytotoxicity accompanied by oxidative stress in rat Sertoli cells: possible role of mitochondrial fractions of Sertoli cells. Toxicol. Appl. Pharmacol. 252, 273-280.

(37) Poli, M., Girelli, D., Campostrini, N., Maccarinelli, F., Finazzi, D., Luscieti, S., Nai, A., and Arosio, P. (2011) Heparin: a potent inhibitor of hepcidin expression in vitro and in vivo. Blood 117, 9971004.

(38) Ganz, T., and Nemeth, E. (2011) The hepcidin-ferroportin system as a therapeutic target in anemias and iron overload disorders. Hematology 2011, 538-542.

(39) Vorrink, S. U., Severson, P. L., Kulak, M. V., Futscher, B. W., and Domann, F. E. (2014) Hypoxia perturbs aryl hydrocarbon receptor signaling and CYP1A1 expression induced by PCB 126 in human skin and liver-derived cell lines. Toxicol. Appl. Pharmacol. 274, $408-416$.

(40) Kang, K. S., Wilson, M. R., Hayashi, T., Chang, C. C., and Trosko, J. E. (1996) Inhibition of gap junctional intercellular communication in normal human breast epithelial cells after treatment with pesticides, $\mathrm{PCBs}$, and $\mathrm{PBBs}$, alone or in mixtures. Environ. Health Perspect. 104, 192-200.

(41) Mrema, E. J., Rubino, F. M., Brambilla, G., Moretto, A., Tsatsakis, A. M., and Colosio, C. (2013) Persistent organochlorinated pesticides and mechanisms of their toxicity. Toxicology 307, 74-88.

(42) Kodavanti, P. R., Ward, T. R., Derr-Yellin, E. C., Mundy, W. R., Casey, A. C., Bush, B., and Tilson, H. A. (1998) Congener-specific distribution of polychlorinated biphenyls in brain regions, blood, liver, and fat of adult rats following repeated exposure to Aroclor 1254. Toxicol. Appl. Pharmacol. 153, 199-210.

(43) Arsenescu, V., Arsenescu, R. I., King, V., Swanson, H., and Cassis, L. A. (2008) Polychlorinated biphenyl-77 induces adipocyte differentiation and proinflammatory adipokines and promotes obesity and atherosclerosis. Environ. Health Perspect. 116, 761-768.

(44) Johnson, K. L., Cummings, A. M., and Birnbaum, L. S. (1997) Promotion of endometriosis in mice by polychlorinated dibenzo-pdioxins, dibenzofurans, and biphenyls. Environ. Health Perspect. 105, $750-755$.

(45) Shan, Q., Huang, F., Wang, J., and Du, Y. (2014) Effects of coexposure to 2,3,7,8-tetrachlorodibenzo-p-dioxin and polychlorinated biphenyls on nonalcoholic fatty liver disease in mice. Environ. Toxicol., DOI: $10.1002 /$ tox.22006
(46) Ahmed, U., Latham, P. S., and Oates, P. S. (2012) Interactions between hepatic iron and lipid metabolism with possible relevance to steatohepatitis. World J. Gastroenterol. 18, 4651-4658.

(47) Ma, R., and Sassoon, D. A. (2006) PCBs exert an estrogenic effect through repression of the Wnt7a signaling pathway in the female reproductive tract. Environ. Health Perspect. 114, 898-904.

(48) Pillon, A., Boussioux, A.-M., Escande, A., Ait-Aïssa, S., Gomez, E., Fenet, H., Ruff, M., Moras, D., Vignon, F., Duchesne, M.-J., Casellas, C., Nicolas, J.-C., and Balaguer, P. (2004) Binding of estrogenic compounds to recombinant estrogen receptor- $\alpha$ : application to environmental analysis. Environ. Health Perspect. 113, 278-284.

(49) Safe, S. H. (2000) Endocrine disruptors and human health-is there a problem? An update. Environ. Health Perspect. 108, 487-493.

(50) Hao, H., d'Alincourt-Salazar, M., Kelley, K. M., Shatnawi, A., Mukherjee, S., Shah, Y. M., and Ratnam, M. (2007) Estrogen-induced and TAFII30-mediated gene repression by direct recruitment of the estrogen receptor and co-repressors to the core promoter and its reversal by tamoxifen. Oncogene 26, 7872-7884.

(51) Hrabia, A., Lesniak, A., and Sechman, A. (2013) In vitro effects of TCDD, PCB126 and PCB153 on estrogen receptors, caspases and metalloproteinase-2 mRNA expression in the chicken shell gland. Folia Biol. (Krakow, Pol.) 61, 277-282.

(52) Choi, S. O., Cho, Y. S., Kim, H. L., and Park, J. W. (2007) ROS mediate the hypoxic repression of the hepcidin gene by inhibiting $\mathrm{C} /$ EBPalpha and STAT-3. Biochem. Biophys. Res. Commun. 356, 312-317.

(53) Lee, H. G., and Yang, J. H. (2012) PCB126 induces apoptosis of chondrocytes via ROS-dependent pathways. Osteoarthr. Cartilage 20, $1179-1185$.

(54) Choi, W., Eum, S. Y., Lee, Y. W., Hennig, B., Robertson, L. W., and Toborek, M. (2003) PCB 104-induced proinflammatory reactions in human vascular endothelial cells: relationship to cancer metastasis and atherogenesis. Toxicol. Sci. 75, 47-56.

(55) Chang, D., Zhang, X. F., Rong, S. Z., Sha, Q., Liu, P. P., Han, T., and Pan, H. Z. (2013) Serum antioxidative enzymes levels and oxidative stress products in age-related cataract patients. Oxid. Med. Cell. Longevity 2013, 587826.

(56) Ganz, T. (2011) Hepcidin and iron regulation, 10 years later. Blood 117, 4425-4433.

(57) Fleming, R. E., and Ponka, P. (2012) Iron overload in human disease. N. Engl. J. Med. 366, 348-359.

(58) Valvi, D., Mendez, M. A., Martinez, D., Grimalt, J. O., Torrent, M., Sunyer, J., and Vrijheid, M. (2012) Prenatal concentrations of polychlorinated biphenyls, DDE, and DDT and overweight in children: a prospective birth cohort study. Environ. Health Perspect. $120,451-457$.

(59) Schecter, A., Tiernan, T., Schaffner, F., Taylor, M., Gitlitz, G., VanNess, G. F., Garrett, J. H., and Wagel, D. J. (1985) Patient fat biopsies for chemical analysis and liver biopsies for ultrastructural characterization after exposure to polychlorinated dioxins, furans and PCBs. Environ. Health Perspect. 60, 241-254.

(60) Xia, Y., Babitt, J. L., Sidis, Y., Chung, R. T., and Lin, H. Y. (2008) Hemojuvelin regulates hepcidin expression via a selective subset of BMP ligands and receptors independently of neogenin. Blood $111,5195-5204$.

(61) Weiss, G., and Goodnough, L. T. (2005) Anemia of chronic disease. N. Engl. J. Med. 352, 1011-1023.

(62) Li, M. H., Zhao, Y. D., and Hansen, L. G. (1994) Multiple dose toxicokinetic influence on the estrogenicity of $2,2^{\prime}, 4,4^{\prime}, 5,5^{\prime}$-hexachlorobiphenyl. Bull. Environ. Contam. Toxicol. 53, 583-590.

(63) Desaulniers, D., Leingartner, K., Wade, M., Fintelman, E., Yagminas, A., and Foster, W. G. (1999) Effects of acute exposure to PCBs 126 and 153 on anterior pituitary and thyroid hormones and FSH isoforms in adult Sprague Dawley male rats. Toxicol. Sci. 47, 158169.

(64) Vorrink, S. U., Hudachek, D. R., and Domann, F. E. (2014) Epigenetic determinants of CYP1A1 induction by the aryl hydrocarbon receptor agonist 3,3',4,4',5-pentachlorobiphenyl (PCB 126). Int. J. Mol. Sci. 15, 13916-13931. 
(65) Vorrink, S. U., Sarsour, E. H., Olivier, A. K., Robertson, L. W., Goswami, P. C., and Domann, F. E. (2014) PCB 126 perturbs hypoxia-induced HIF-1alpha activity and glucose consumption in human HepG2 cells. Exp. Toxicol. Pathol. 66, 377-382.

(66) Meynard, D., Babitt, J. L., and Lin, H. Y. (2014) The liver: conductor of systemic iron balance. Blood 123, 168-176.

(67) Xue, X., and Shah, Y. M. (2013) Intestinal iron homeostasis and colon tumorigenesis. Nutrients 5, 2333-2351.

(68) Brunet, S., Thibault, L., Delvin, E., Yotov, W., Bendayan, M., and Levy, E. (1999) Dietary iron overload and induced lipid peroxidation are associated with impaired plasma lipid transport and hepatic sterol metabolism in rats. Hepatology 29, 1809-1817.

(69) Graham, R. M., Chua, A. C., Carter, K. W., Delima, R. D., Johnstone, D., Herbison, C. E., Firth, M. J., O’Leary, R., Milward, E. A., Olynyk, J. K., and Trinder, D. (2010) Hepatic iron loading in mice increases cholesterol biosynthesis. Hepatology 52, 462-471.

(70) Foretz, M., Foufelle, F., and Ferre, P. (1999) Polyunsaturated fatty acids inhibit fatty acid synthase and spot-14-protein gene expression in cultured rat hepatocytes by a peroxidative mechanism. Biochem. J. 341, 371-376.

(71) Burstein, H., Harris, J., and Morrow, M. (2011) Malignant tumors of the breast, in DeVita, Hellman, and Rosenberg's Cancer: Principles \& Practice of Oncology (DeVita, V. T., Jr., Lawrence, T. S., and Rosenberg, S. A., Eds.) 9th ed., Lippincott Williams \& Wilkins, Philadelphia, PA.

(72) Boonyaratanakornkit, V., and Edwards, D. P. (2007) Receptor mechanisms mediating non-genomic actions of sex steroids. Semin. Reprod. Med. 25, 139-153.

(73) Carroll, J. S., and Brown, M. (2006) Estrogen receptor target gene: an evolving concept. Mol. Endocrinol. 20, 1707-1714.

(74) Torti, S. V., and Torti, F. M. (2013) Cellular iron metabolism in prognosis and therapy of breast cancer. Crit. Rev. Oncog. 18, 435-448. (75) Zhang, C., and Zhang, F. (2014) Iron homeostasis and tumorigenesis: molecular mechanisms and therapeutic opportunities. Protein Cell 6, 88-100. 